\title{
Analysis and Prediction of Compressive Properties for Steel Fiber-and-Nanosilica-Reinforced Crumb Rubber Concrete
}

\author{
Danying Gao, ${ }^{1,2}$ Tao Zhang $\mathbb{D}^{1},{ }^{1}$ Yihong Wang $\mathbb{D}^{1},{ }^{1}$ Yiming Kong, ${ }^{1}$ Dawei Li, ${ }^{1}$ and Yang Meng ${ }^{1}$ \\ ${ }^{1}$ School of Civil Engineering, Zhengzhou University, No. 100, Science Road, Zhengzhou, Henan 450001, China \\ ${ }^{2}$ Henan University of Engineering, No. 1, Xianghe Road, Zhengzhou, Henan 451191, China \\ Correspondence should be addressed to Tao Zhang; 961480006@qq.com and Yihong Wang; 531066753@qq.com
}

Received 25 September 2019; Revised 26 November 2019; Accepted 18 December 2019; Published 5 March 2020

Academic Editor: Faiz U.A. Shaikh

Copyright (C) 2020 Danying Gao et al. This is an open access article distributed under the Creative Commons Attribution License, which permits unrestricted use, distribution, and reproduction in any medium, provided the original work is properly cited.

The disposal of waste tire rubber has gained more attention from the viewpoint of green, environmental protection, and sustainability. Numerous attempts have been stated on the properties of crumb rubber concrete (CRC) and observed that there is a large reduction of compressive strength and elastic modulus of $\mathrm{CRC}$ with the increase of the rubber substitution rate. Based on the CRC with the crumb rubber volume content of 5\%, the steel fibers and nanosilica were added to CRC to make steel fiber-andnanosilica-reinforced crumb rubber concrete (SFNS-CRC) in this paper. The effects of the steel fiber volume content and nanosilica content on the compressive properties of SFNS-CRC were studied, including compressive strength, elastic modulus, peak strain, compression toughness, and failure pattern. The test results indicated that the modulus of elasticity and compressive strength of SFNS-CRC have the increasing tendency with the addition of steel fibers and nanosilica. Moreover, the peak strains have a significant increase with the increase of the steel fiber content and nanosilica replacement ratio. The compressive stressstrain curves of SFNS-CRC gradually plump with the increase of the steel fibers and nanosilica. Finally, the prediction formulas for the compressive strength, elastic modulus, and peak strain of SFNS-CRC were set up. A simple predicted model of the stress-strain curve for SFNS-CRC was proposed, which considers the effect of steel fibers and nanosilica.

\section{Introduction}

The rapid development of automobile industry has produced a lot of waste tire rubber. Disposal of waste tires has been a major environmental problem for the countries around the world. Recycling of used tires is becoming more and more important with the increasing landfills for used tires. It is urgent to seek the possible way to take advantage of waste tire rubber. It has been recognized that crushing waste tires into particles of different sizes and adding them to concrete is a sustainable and environmentally healthy way [1]. The concrete containing different rubber crumb particle sizes and contents was studied in depth in the past 30 years. The studies [2-4] found that the rubber content and size have a significant effect on the mechanical properties of concrete, and the compressive strength of rubber concrete decreases with the increase of the rubber content and particle size. Moreover, rubber particles also cause the reduction of concrete elastic modulus. However, it was reported that rubber can improve some mechanical properties of concrete such as brittleness resistance property, freezing-thawing, impact resistance, and toughness [5-9]. Thus, the rubberized concrete and rubberized asphalt were mainly used in roads and bridges due to their impact resistance and buffering properties [10,11]. The application of concrete with high rubber content in the building structure is limited because it greatly reduces the strength of concrete. In order to use CRC for the structural members and layers with high stress, it is necessary to increase the compressive and splitting tensile strength of CRC and to set up its constitutive equation. $\mathrm{Li}$ et al. [12] conducted the uniaxial compressive tests on the CRC with low rubber volume content; the uniaxial compressive constitutive models of low-volume rubber concrete were established and further improved through the incorporation of rubber particles equivalent to the sand ratio factor to predict the stress-strain relationship of rubber 
concrete and promote the application of rubber concrete in structural design.

As a new type of reinforced material of concrete, steel fiber has excellent mechanical properties. Considerable studies have shown that adding steel fibers into concrete can improve the mechanical performance of concrete structural components, by delaying the development of microcracks into macrocracks, hindering the development of macrocracks and leading to stress redistribution [13-20]. $\mathrm{Li}$ and $\mathrm{Li}$ [21] studied the effects of $0.9 \%$ steel fiber volume fraction and $5 \%$ rubber particle content on the mechanical properties of high-strength concrete, including flexure, compression, and seismic behavior. It was found that, after adding $0.9 \%$ steel fibers into CRC, the compressive strength and elastic modulus of CRC increase slightly, while its flexural strength increases significantly. Ahmed et al. [22] compared the compression strength, modulus of elasticity, and stressstrain of rubberized steel fiber concrete with those of rubberized normal concrete. According to the results of analysis for the compressive test, it was reported that crumb rubber and steel fibers considerably affect the toughness of concrete. Moreover, Fu showed that the flexural toughness of steel fiber-reinforced rubberized concrete is highly enhanced due to the combined use of crumb rubber and steel fibers in the concrete mixture and the bridging effect of fibers and high elasticity of rubber [23].

Incorporating the waste crumb rubber into the concrete to form $\mathrm{CRC}$ is an effective way to realize the resource recycling. Generally, the addition of crumb rubber may increase the deformability, fatigue performance, durability, shock absorption, and noise reduction performance of concrete but decrease its compressive strength and tensile strength. Recently, it has been found that the rubber content does not affect the bridging effect of the steel fibers on the surrounding concrete, and the positive synergy between the steel fibers and the rubber particles has the advantages of enhancing the shrinkage resistance and improving the fracture properties. However, the addition of steel fibers also increases the interfacial area of the concrete, which inevitably increases the presence of microscopic and macroscopic defects between the interfaces and weakens the strength. Adding the nanomaterial into concrete is an efficient means to develop durable and environmentally friendly highperformance concrete because nanosilica can promote the hydration of cement slurry and the formation of early calcium hydroxide, reduce the porosity of cement slurry and the dissolution of calcium, accelerate the pozzolanic reaction, make the microstructure of concrete more dense, and improve the strength, permeability, and wear resistance of concrete [24-31]. In addition, the inclusion of nanomaterials can refine the size of the pores and densify the interfacial transition zone between the cement matrix and the aggregate in hardened rubber concrete $[32,33]$. Therefore, the highperformance CRC reinforced by steel fibers and nanomaterials has the high compressive and splitting tensile strength, which meets the requirements of the engineering structure for high performance of concrete. In order to probe the coupling effect of crumb rubber, steel fibers, and nanosilica on the properties of concrete, this paper mainly investigated the compressive strength, elastic modulus, compression toughness, and stress-strain curve of steel fiberand-nanosilica-reinforced crumb rubber concrete (SFNSCRC) through the uniaxial compression test and finally presented a stress-strain model of SFNS-CRC subjected to uniaxial compression.

\section{Experimental Program}

2.1. Materials. The constituents of the CRC mixture used in the test were cement, fine aggregates, coarse aggregates, steel fibers, nanosilica, water, and crumb rubber with a diameter of 1-2 mm [34]. Portland cement (P. O 42.5) was used in all mixtures, which meets the Chinese standard "GB175-2007" [35]. The chemical composition and properties of cement are shown in Table 1 . The coarse aggregate with a particle size of $5-20 \mathrm{~mm}$ and fine aggregate with a fineness modulus of 3.0 from riversides were used, which is compatible with the Chinese standard "GBT14684-2011" [36]. The rubber particle size was $1 \sim 2 \mathrm{~mm}$, which was made by the mechanical crushing of the discarded rubber tire. The particle size distributions of the fine aggregate, coarse aggregate, and crumb rubber are shown in Figure 1. The steel fiber used was a kind of hooked one at both ends with the tensile strength of $1345 \mathrm{MPa}$. Table 2 lists the geometrical and mechanical characteristics of the steel fiber. The nanosilica was white powder with an average particle size of $30 \mathrm{~nm}$, and its apparent density was 40-60 g/l. The properties of nanosilica are given in Table 3. The amorphous structure of nanosilica was revealed by the XRD pattern, as shown in Figure 2. The brown yellow powder of the naphthalene water reducer with $25 \%$ water-reducing ratio was adopted to ensure that the slump of concrete was within the range of $20 \sim 70 \mathrm{~mm}$. The used materials and CRC mixture slump test are shown in Figure 3.

2.2. Experimental Design and Mixing Proportion. The research for the reinforcing effects of the steel fibers and the nanosilica on the compression properties of CRC is the main purpose of the test. The strength grade C35 of CRC with 5\% crumb rubber and the compressive strength of $35 \mathrm{MPa}$ to $45 \mathrm{MPa}$ was chosen as the control group. The mix proportions of crumb rubber were designed by following the principle of the volume percentage method, where $5 \%$ crumb rubber meant adding $50 \mathrm{~kg}$ crumb rubber into $1 \mathrm{~m}^{3}$ concrete. Based on CRC with $5 \%$ of the crumb rubber volume content, four steel fiber volume contents $\left(\nu_{f}\right)(0 \%$, $0.5 \%, 1.0 \%$, and $1.5 \%)$ were taken into consideration. Moreover, when the volume percentage of the steel fiber was $1.0 \%$, three nanosilica replacement ratios $\left(\nu_{N}\right)(0 \%, 1 \%$, and $2 \%$ by replacing the cement) were adopted. Details of the mixture proportion of SFNS-CRC are listed in Table 4.

2.3. Specimen Preparation and Curing. SFNS-CRC was mixed through a shaft mixer with $60 \mathrm{~L}$ capacity. All aggregates and steel fibers were put together and mixed for 2 minutes to ensure the steel fibers were uniformly dispersed. For the mixture of SFNS-CRC with the steel fiber content of 
TABLE 1: Chemical composition and properties of cement.

\begin{tabular}{|c|c|c|c|c|c|c|c|c|}
\hline Specific surface area $\left(\mathrm{m}^{2} / \mathrm{kg}\right)$ & Specific gravity $\left(\mathrm{kg} / \mathrm{m}^{3}\right)$ & $\begin{array}{r}\text { Settin } \\
(\mathrm{m}\end{array}$ & $\begin{array}{l}\text { g time } \\
\text { in) }\end{array}$ & $\mathrm{SO}_{3}(\%)$ & $\mathrm{MgO}(\%)$ & $\mathrm{Cl}(\%)$ & Loss on ignition (\%) & $\begin{array}{c}\text { Mortar } \\
\text { strength }(\mathrm{MPa})\end{array}$ \\
\hline 350 & 3100 & $\begin{array}{c}\text { Initial } \\
172\end{array}$ & $\begin{array}{c}\text { Final } \\
230\end{array}$ & 2.26 & 2.21 & 0.015 & 3.82 & $\begin{array}{cc}3 \text { days } & 28 \text { days } \\
25.6 & 45.8\end{array}$ \\
\hline
\end{tabular}

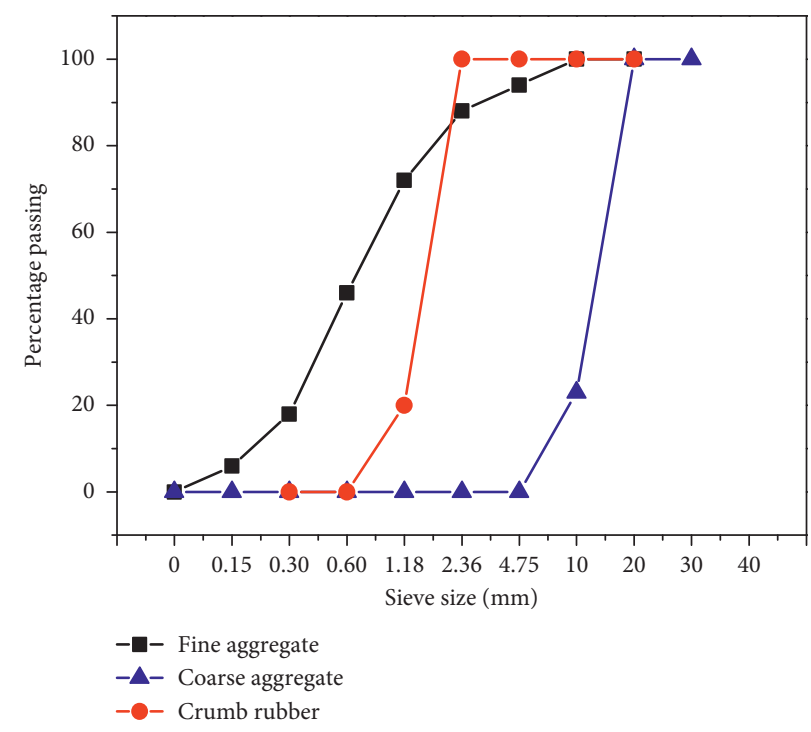

FIgURe 1: Particle size distribution of aggregates.

TABLe 2: Geometrical and mechanical specifications of the steel fiber.

\begin{tabular}{lcccc}
\hline Fiber type & Length $\mathrm{d}_{f}(\mathrm{~mm})$ & Diameter $l_{f}(\mathrm{~mm})$ & Aspect ratio $\left(l_{f} / \mathrm{d}_{f}\right)$ & Tensile strength $(\mathrm{MPa})$ \\
\hline 3D 35 & 0.55 & 35 & 65 & 1345 \\
\hline
\end{tabular}

TABle 3: Properties of nanosilica.

\begin{tabular}{lccccc}
\hline Appearance & Purity $(\%)$ & Diameter $(\mathrm{nm})$ & Specific surface area $\left(\mathrm{m}^{2} / \mathrm{g}\right)$ & Density $(\mathrm{g} / \mathrm{L})$ & $\mathrm{pH}$ value \\
\hline High-dispersive white powder & $\geq 99.5$ & 30 & $200 \pm 10$ & $40 \sim 60$ & $5.0 \sim 7.0$ \\
\hline
\end{tabular}

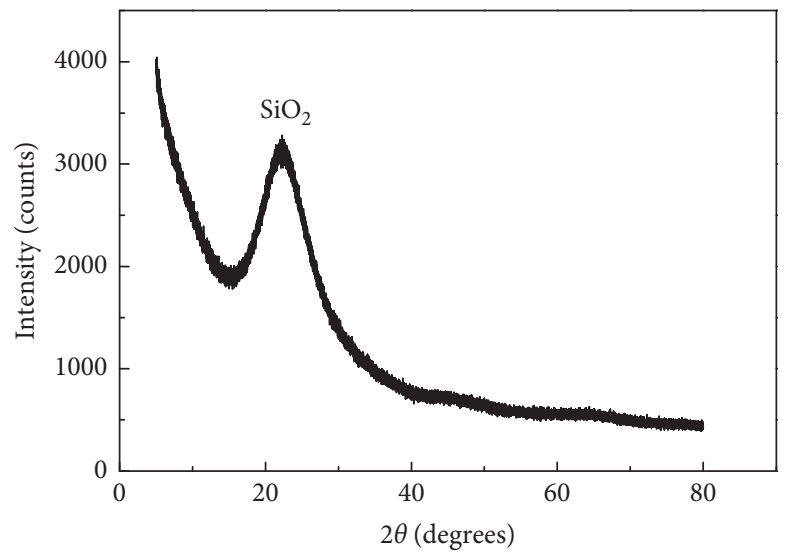

FIGURE 2: XRD pattern of nanosilica.

$1.5 \%\left(117 \mathrm{~kg} / \mathrm{m}^{3}\right)$, the mixing times were extended until the mixture was dispersed to reduce the possibility of fiber balling due to uneven stirring. Then, the crumb rubbers and cement were added and mixed for another 2 minutes. Additionally, for the mix proportion including nanosilica, the nanosilica was added to water in advance and stirred 


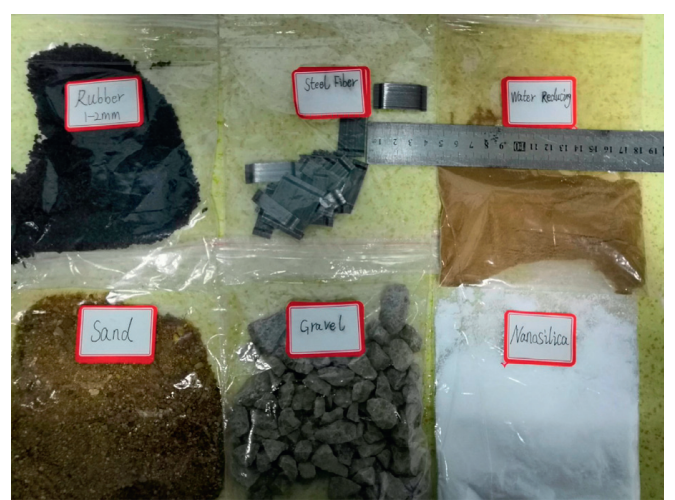

(a)

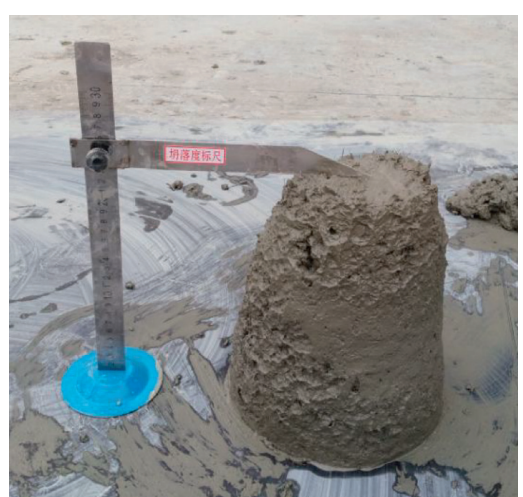

(b)

Figure 3: (a) Materials. (b) Concrete slump test.

TABLE 4: Mix proportions of SFNS-CRC (unit: $\mathrm{kg} / \mathrm{m}^{3}$ ).

\begin{tabular}{|c|c|c|c|c|c|c|c|c|}
\hline Group & Crumb rubber & Cement & Coarse aggregate & Fine aggregate & Water & Water reducer & Steel fiber & Nanosilica \\
\hline CR5SF0 & 50 & 400 & 703 & 1004 & 169 & 4 & 0 & - \\
\hline CR5SF0.5 & 50 & 419 & 705 & 1060 & 177 & 4.5 & $39(0.5 \%)$ & - \\
\hline CR5SF1 & 50 & 438 & 654 & 1045 & 185 & 5 & $78(1 \%)$ & - \\
\hline CR5SF1.5 & 50 & 457 & 604 & 1029 & 193 & 5 & $117(1.5 \%)$ & - \\
\hline CR5SF1NS1 & 50 & 433.62 & 654 & 1045 & 185 & 5 & $78(1 \%)$ & $4.38(1 \%)$ \\
\hline CR5SF1NS2 & 50 & 429.24 & 654 & 1045 & 185 & 5 & $78(1 \%)$ & $8.76(2 \%)$ \\
\hline
\end{tabular}

Note: CR5SF1NS1 means the specimen with CR $=5 \%, v_{N}=1 \%$, and $v_{f}=1 \%$.

uniformly. Then, the water reducer was added into water and stirred evenly. Finally, the water was added to the mixture and mixed for another 2 minutes. After the end of the mixing process, the slumps of concrete mixtures were tested immediately. For each group of SFNS-CRC, nine $150 \mathrm{~mm} \times 150 \mathrm{~mm} \times 300 \mathrm{~mm}$ prism specimens were cast for testing the prism compressive strength $f_{c}$, elastic modulus $E_{c}$, and stress-stain curves, respectively, and three $150 \mathrm{~mm} \times 150 \mathrm{~mm} \times 150 \mathrm{~mm}$ cube specimens for testing cubic compressive strength $f_{\mathrm{cu}}$. All specimens were cast by using steel moulds and put on a vibration table for 20 -second vibration to ensure compaction, demoulded after 24 hours, and then cured in a moisture room at approximately $95 \%$ relative humidity and $20^{\circ} \mathrm{C}$ temperature. The tests were performed after 28 days.

2.4. Test Procedures. The compressive strength, the modulus of elasticity, and the stress-strain curves were tested according to the specifications in Chinese standards GB/ T50081 [37] and CECS13:2009 [38], respectively. Both the tests of compressive strength and modulus of elasticity were conducted in an electrohydraulic servo-controlled machine with a capacity of $3000 \mathrm{kN}$. The loading rate for the tests of compressive strength and modulus of elasticity tests was $0.5 \mathrm{MPa} / \mathrm{s}$. Whitney [39] pointed out that sudden failure of the specimen was caused by the insufficient rigidity of the testing machine. In this paper, the four strong springs, as shown in Figure 4, were used as a rigid element to improve the stiffness of the whole test device, and the complete stressstrain curves were obtained. The specific loading scheme of the test was as follows: firstly, the specimens were taken out from the curing room, wiped to make them clean, checked whether the appearance was intact, and measured for the size to the accuracy of $1 \mathrm{~mm}$; secondly, two displacement transducers were attached to the opposite sides of the section of the prism specimen to measure the deformation, and the measured load and deformation were recorded with a data acquisition system at a rate of once per second; thirdly, the preloading up to the $40 \%$ of prism compressive strength was carried out before formal loading at the loading speed of $0.6 \mathrm{MPa} / \mathrm{s}$, while the displacement transducers on both sides were observed. The difference between the measured values of two displacement transducers could not exceed $30 \%$. Otherwise, the adjustment for specimens should be carried out; fourthly, the formal loading was carried out after the preloading was completed. In the formal loading, the loading speed of $0.5 \mathrm{MPa} / \mathrm{s}$ was first used to $30 \%$ of the peak load, and then the loading speed was taken as $0.2 \mathrm{~mm} / \mathrm{min}$ by displacement control, as shown in Figure 4.

\section{Test Results and Discussion}

The test results of the slump, cube compressive strength $\left(f_{\mathrm{cu}}\right)$, prism compressive strength $\left(f_{c}\right)$, modulus of elasticity $\left(E_{c}\right)$, peak deformation $\left(d_{c}\right)$ corresponding to the peak load, and peak strain $\varepsilon_{c}$ corresponding to the peak stress of SFNSCRC are listed in Table 5, in which each value is an average of the test results from three specimens.

3.1. Effects of Steel Fibers and Nanosilica on Compressive Properties. The relationships between compressive properties of SFNS-CRC and steel fiber content are shown in 


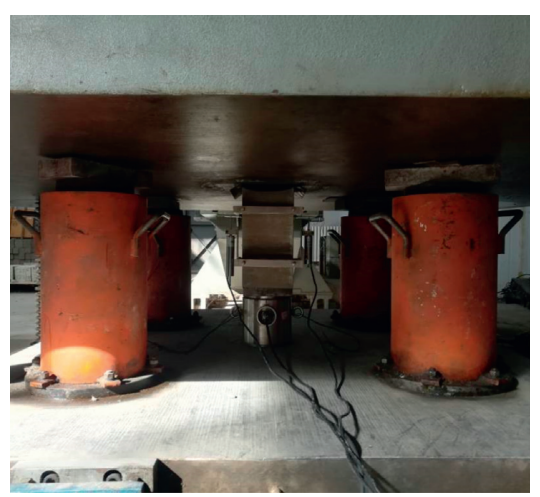

(a)

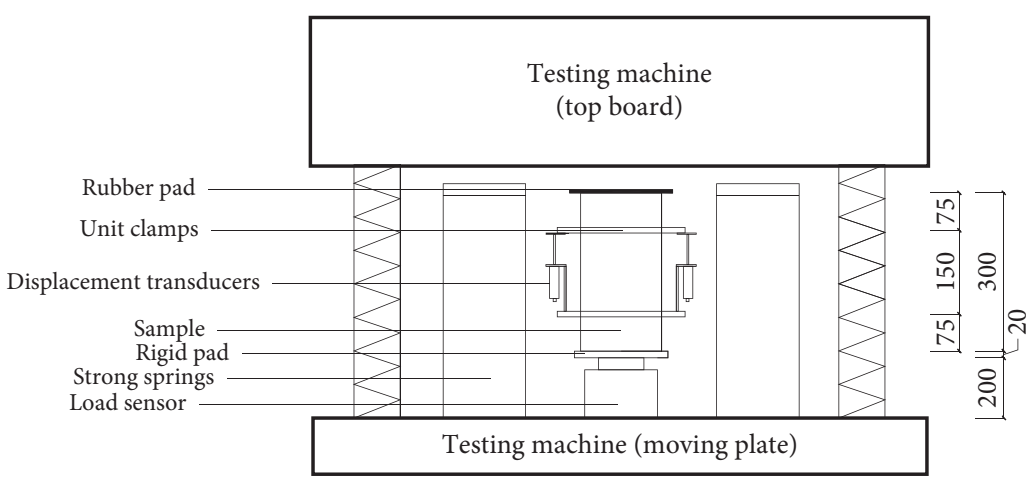

(b)

Figure 4: Testing arrangement for stress-strain curves: (a) general view; (b) layout.

TABLe 5: Test results.

\begin{tabular}{lcccccccc}
\hline Group & Slump $(\mathrm{mm})$ & $f_{\mathrm{cu}}(\mathrm{MPa})$ & $f_{c}(\mathrm{MPa})$ & $f_{c} / f_{\mathrm{cu}}$ & $d_{c}(\mathrm{~mm})$ & $E_{c}(\mathrm{GPa})$ & $R_{e .1 .0}$ & $\varepsilon_{c}\left(\times 10^{-3}\right)$ \\
\hline CR5SF0 & 70 & 35.6 & 26.8 & 0.73 & 0.224 & 22.2 & 0.349 \\
CR5SF0.5 & 68 & 38.6 & 29.2 & 0.75 & 0.294 & 23.6 & 0.538 \\
CR5SF1 & 65 & 40.3 & 31.9 & 0.79 & 0.393 & 25.2 & 0.716 \\
CR5SF1.5 & 50 & 37.6 & 28.4 & 0.75 & 0.439 & 25.6 & 0.761 & 2.62 \\
CR5SF1NS1 & 43 & 45.1 & 35.4 & 0.78 & 0.459 & 28.7 & 0.741 \\
CR5SF1NS2 & 28 & 46.4 & 36.2 & 0.78 & 0.581 & 30.4 & 0.811 & 3.06 \\
\hline
\end{tabular}

Note: $R_{e .1 .0}$ stands for the toughness index.

Figure 5. As shown in Figure 5(a), compared with CRC without steel fibers, as $\nu_{f}$ increases from 0 to $0.5 \%, 1.0 \%$, and $1.5 \%$, the increment rate for $f_{\mathrm{cu}}$ is $8.4 \%, 13.2 \%$, and $5.6 \%$, respectively; it is $8.9 \%, 19.0 \%$, and $6.0 \%$ for $f_{c}$. The ratio of the compressive strength of the prism to that of the cube is about 0.76 for SFNS-CRC and CRC, which is slightly lower than the value of 0.85 for normal concrete [37]. Zheng et al. [40] reported the ratio of cylinder compressive strength to cube compressive strength for rubberized concrete is related to the rubber content and size. In addition, with the addition of steel fibers, the steel fiber has a similar effect on the compressive properties of CRC and normal concrete [41]. The effect of addition of steel fibers on compressive strength ranges from 0 to $25 \%$ as reported by Balaguru and Shah [42]. However, $\mathrm{Fu}$ et al. [23] found that the effect of concrete containing rubber crumbs on compressive strength depends on the rubber content. The decline in compressive strength due to a high amount of fiber dosage in CRC might be associated with the poor compactness [43].

As shown in Figures 5(b) and 5(c), the values of $E_{c}$ and $\varepsilon_{c}$ also gradually increase with the increase of $\nu_{f}$. $E_{c}$ increases from $22.2 \mathrm{GPa}$ to $25.6 \mathrm{GPa}$ and $\varepsilon_{c}$ increases from $1.5 \times 10^{-3}$ to $29.3 \times 10^{-3}$ with the increase of $\nu_{f}$ from 0 to $1.5 \%$, and the increasing rate is $15 \%$ and $95 \%$, respectively. Obviously, the steel fiber has little effect on $E_{c}$ of CRC, and the value of $E_{c}$ for CRC with steel fibers was still smaller than that for plain concrete. This is due to the fact that steel fibers play a minor role in the elastic phase of the concrete. Fu et al. [23] pointed out that the modulus of elasticity of CRC is dominated by the crumb rubber content. However, the growth of peak strain is much higher than that in other literature studies [16]. For rubber and steel fiber addition, the effect of rubber [12] and steel fibers on the deformation of concrete exceeds the effect of rubber and steel fibers on the strength of concrete, which causes a large deformation of SFNS-CRC. This is attributed to the fact that steel fibers can inhibit the development of cracks in concrete and hinder the development of macrocracks. The stress concentration in SFNS-CRC can be avoided by changing the direction of major fractures through the bridging action of steel fibers.

For a group of specimens with $v_{f}=1 \%$, as $\nu_{N}$ increases from $0 \%$ to $1 \%$ and $2 \%$, the increment rate for $f_{\mathrm{cu}}$ is $11.9 \%$ and $15.1 \%$, respectively; it is $11 \%$ and $13.5 \%$ for $f_{c}$, as shown in Figure 6(a). The increment rate for $E_{c}$ is $13.9 \%$ and $20.6 \%$ and that for $\varepsilon_{c}$ is $16.8 \%$ and $47.7 \%$, respectively, as shown in Figures $6(\mathrm{~b})$ and $6(\mathrm{c})$. The measured interfacial transition zone (ITZ) between the rubber particle and concrete is shown in Figure 7. It can be found that the thickness of the ITZ becomes thinner with the addition of nanosilica. The loss in strength of concrete with incorporation of crumbs is attributed to the increased thickness of the ITZ between the hardened paste matrix and crumb rubber particles which causes poor bonding between them and leads to the formation of microcracks and consequently premature failure $[4,32,33]$. This is due to the hydrophobic properties of crumb rubber, which traps air around it, leading to an increase in the air content and consequently an increase in the ITZ thickness. However, as the nanosilica amount increases, the ITZ thicknesses decrease, as shown clearly in Figure 7(b). The main reason is that nanosilica has the ability to fill up nanovoids and also refine the pore system which makes the hardened microstructure of the concrete mix denser [31]. In 


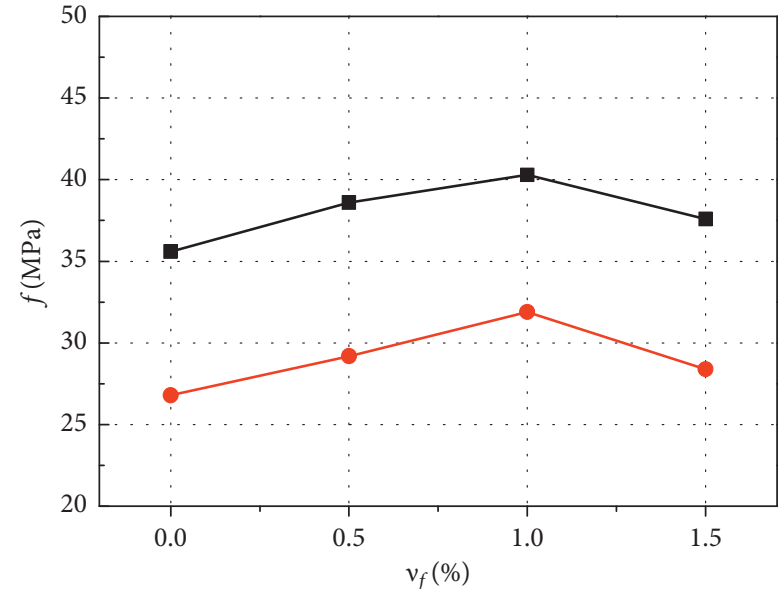

$\rightarrow-f_{\mathrm{cu}}$

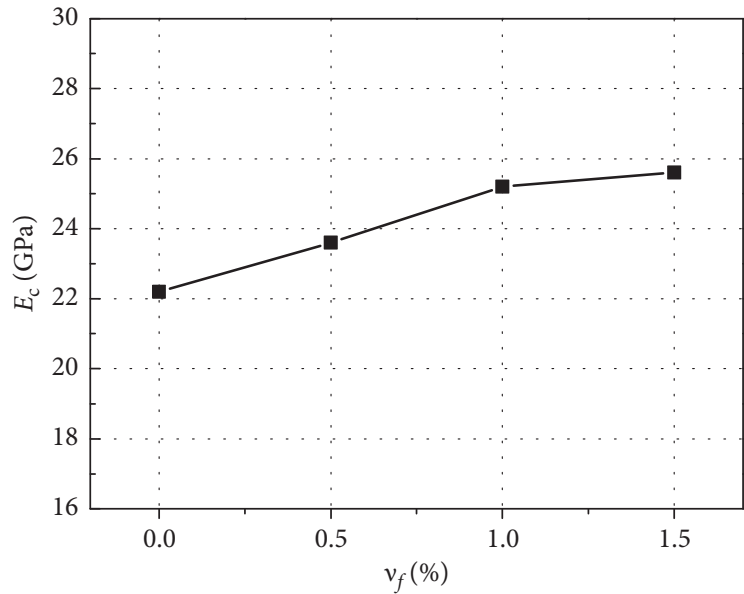

(a)

(b)

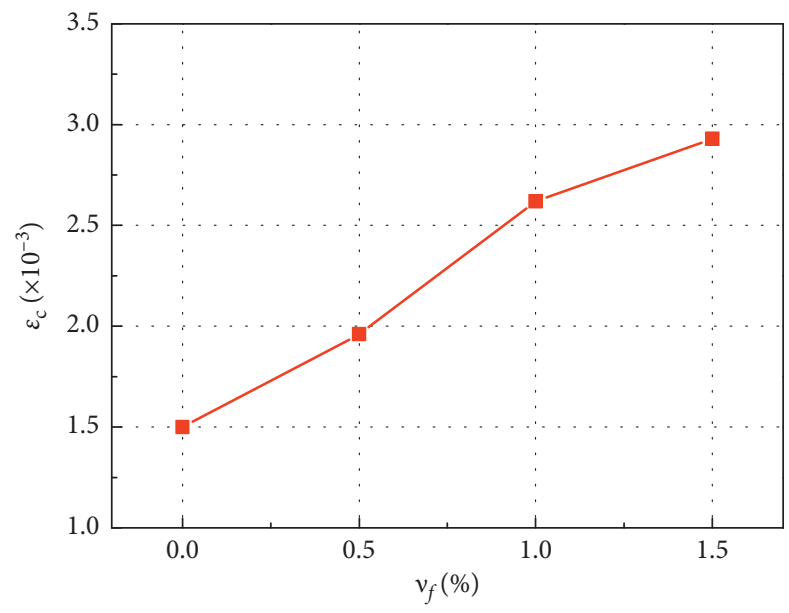

(c)

Figure 5: Effects of the steel fiber content: (a) $f_{\text {cu }}$ and $f_{c}$; (b) $E_{c}$; (c) $\varepsilon_{c}$.
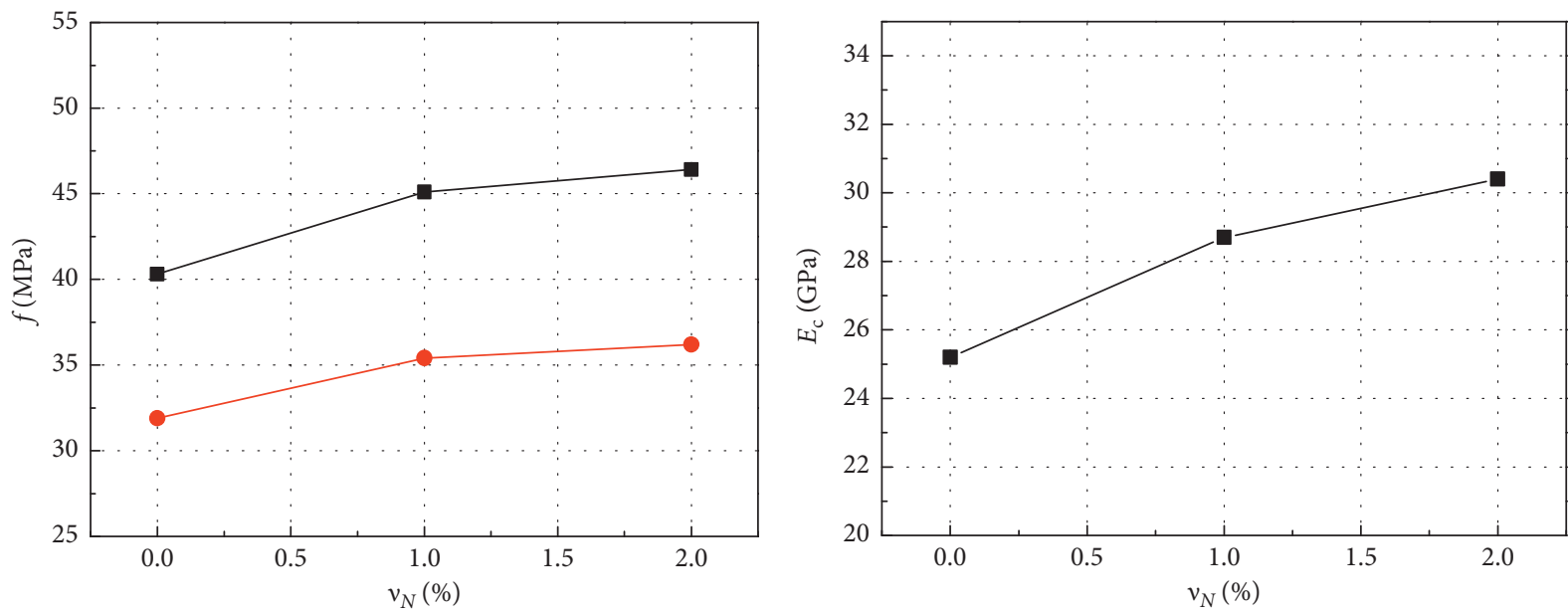

$-f_{\mathrm{cu}}$

$\rightarrow f_{\mathrm{c}}$

(a)

(b)

FIgURE 6: Continued. 


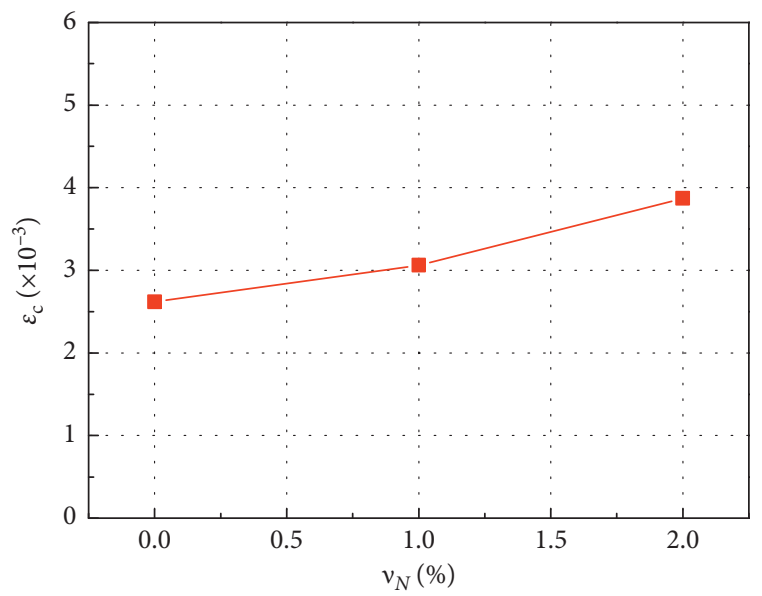

(c)

FIgURE 6: Effects of the nanosilica content: (a) $f_{\mathrm{cu}}$ and $f_{c}$; (b) $E_{c}$; (c) $\varepsilon_{\mathrm{c}}$.

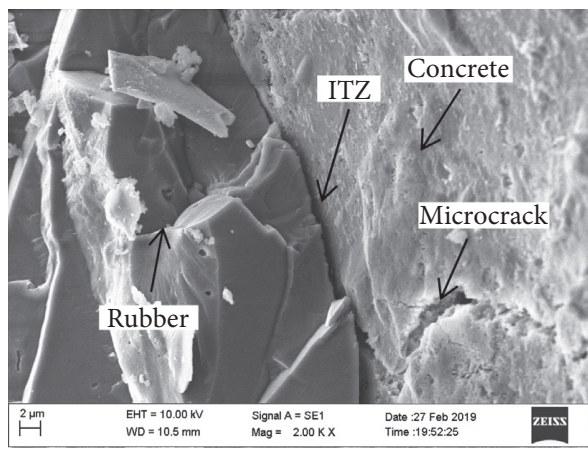

(a)

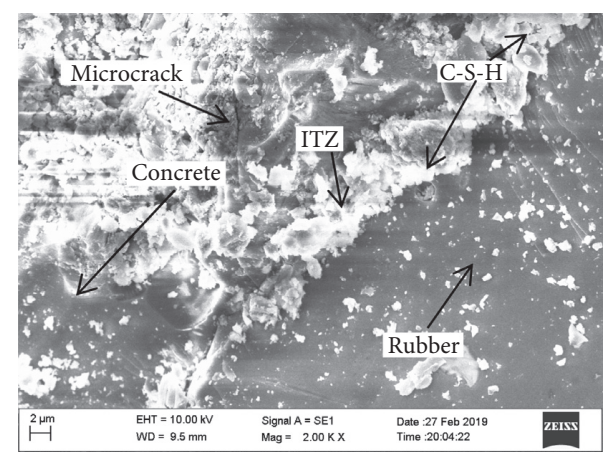

(b)

Figure 7: Representative SEM images of SFNS-CRC: (a) $v_{N}=0 \%$; (b) $v_{N}=1 \%$.

addition, the high pozzolanic reactivity of nanosilica enables it to react and consume the surplus $\mathrm{Ca}(\mathrm{OH})_{2}$ and produce extra C-S-H gel which is the main compound for the strength development and densification of the interfacial transition zone $[32,33]$.

\subsection{Effects of Steel Fibers and Nanosilica on Load-Deformation} Curves. The load-deformation curves of SFNS-CRC with different steel fiber volume contents are compared in Figure 8(a). It is found from the test that the ascending shape of SFNS-CRC load-deformation curves is similar, while the slope of descending portions on the curves is decreasing with the increase of $v_{f}$ and going to converge to the horizontal. It can also be seen from the figure that, with the increase of $v_{f}$, both the peak load and the peak deformation of SFNS-CRC increase significantly. With the addition of steel fibers, the curves are plumper and have better energy absorption capacity. This similar morphological change can be found in previous research [22,23].

For a group of specimens with $v_{f}=1 \%$, the load-deformation curves of SFNS-CRC with different nanosilica contents are compared in Figure 8(b). It is found that the ascending and descending branches of these curves are similar, but the curvature of the curves near the peak load decreases with the increase of $v_{N}$. It can also be seen from the figure that, with the increase of $v_{N}$, both the peak load and the peak deformation of SFNS-CRC increase significantly. In addition, the descending segment has a larger area with the increase of $v_{N}$. This indicates that the addition of nanosilica can significantly improve the prepeak and postpeak deformability of SFNS-CRC.

3.3. Effects of Steel Fibers and Nanosilica on Compression Toughness. The area under the stress-strain curve is a measure of toughness of the material. The most significant effect of adding steel fibers and nanosilica is to improve the toughness of concrete. Compression work $\left(\mathrm{W}_{1.0}\right)$ and toughness index $\left(R_{e .1 .0}\right)$ can be used to evaluate the axial compression toughness of steel fiber-reinforced concrete [38], where $W_{1.0}$ is defined as the area under the load-deformation curve with the deformation range from 0 to $l_{0} \times 1.0 \%$, in which $l_{0}$ is the gauge length $(150 \mathrm{~mm}$ in this 


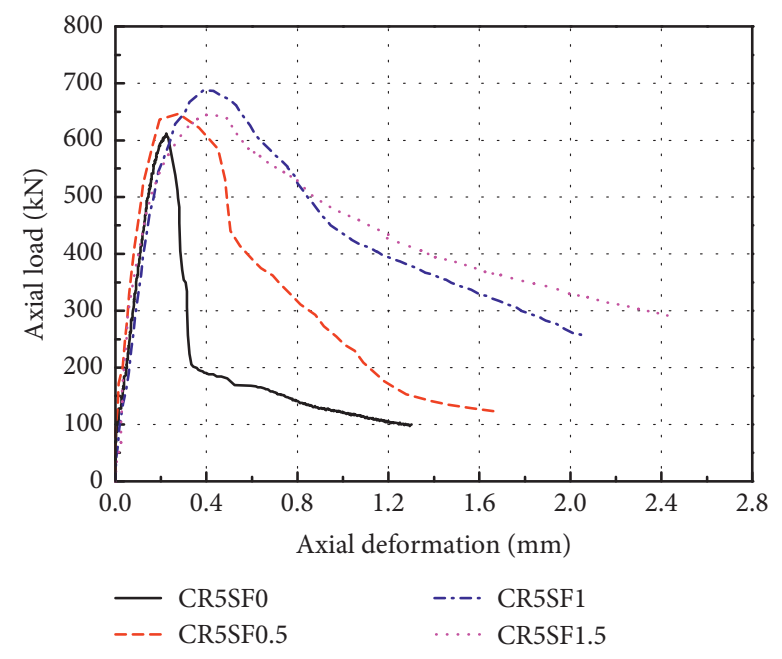

(a)

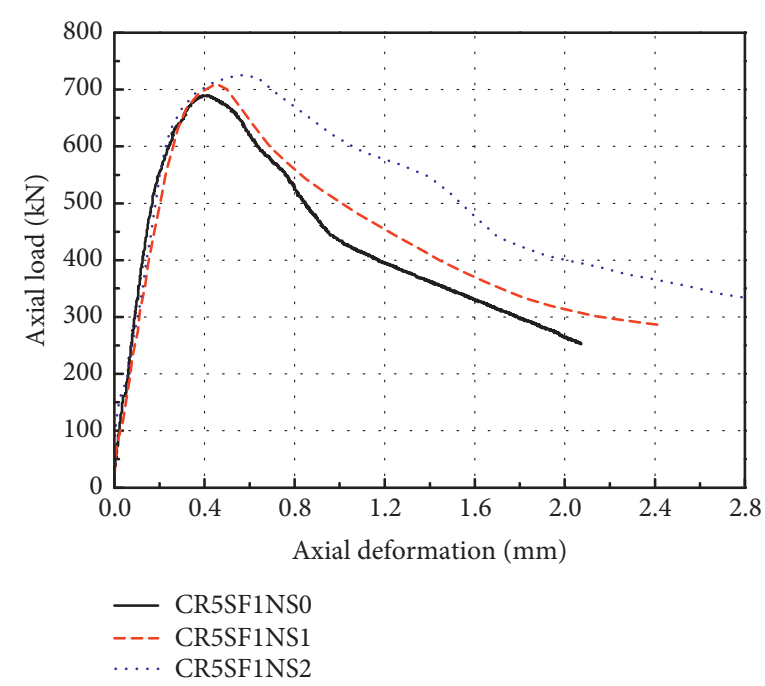

(b)

FIgURE 8: Load-deformation curves of SFNS-CRC with different (a) $v_{f}$ and (b) $v_{N}$.

study). The toughness index $R_{\text {e.1.0 }}$ is an indicator of the energy absorption capacity of the specimen and is defined as follows:

$$
R_{e .1 .0}=\frac{W_{1.0}}{F_{\max } \times l_{0} \times 1.0 \%},
$$

where $F_{\max }$ is the peak load.

The results of the toughness index $R_{e .1 .0}$ calculated by equation (1) for each group are listed in Table 5. Compared with the toughness index of CRC, the increasing ratios of the toughness index of CRC with fibers are 54\%, 105.2\%, and $118.1 \%$ when $v_{f}$ increases from 0 to $1.5 \%$. When the nanosilica content increases from 0 to $2 \%$, the toughness index increases from 0.716 to 0.811 and the increasing ratio reaches $13.2 \%$. It means that steel fibers and nanosilica can remarkably improve the toughness and energy absorption capability of CRC. The toughening effect of steel fibers on $\mathrm{CRC}$ is greater than that of nanosilica. The previous research has shown that the toughness index can be increased with the increase of the fiber volume and aspect ratio [44].

3.4. Effects of Steel Fibers and Nanosilica on Failure Mode. From the failure modes of prism specimens shown in Figure 9, it can be observed that the addition of steel fibers has a significant effect on the failure mode of CRC. For CRC, when approaching to the peak load, one crack or several longitudinal parallel cracks start to appear in the central portion of the specimen and then propagate quickly. Finally, the specimens are split into several parts. The CRC specimens with steel fibers show the typical oblique shear failure mode. With the increasing steel fiber content, the number of cracks increases and the width of the major macrocracks enlarges. Compared to the one without steel fibers, the CRC specimens with steel fibers exhibit more and thinner vertical cracks at failure. This is because steel fibers with adequate anchorage can be used to bridge cracks and prevent catastrophic collapse [18] and further promote the cracks to develop and widen. When nanosilica is added into CRC, the cracks are distributed more evenly and more scattered rather than being relatively concentrated and more small cracks appear near the macrocracks. The cement mortars on the surface of concrete are peeled, which do not fell off, as shown in Figures 9(e) and 9(f). The phenomenon may be mainly attributed to the formation of stronger ITZs due to the pozzolanic and filler effects of nanosilica.

\section{Prediction of Compressive Properties}

4.1. Compressive Strength. Based on the test data from this paper and previous research $[22,23,30,32,33,43,45-48]$, the relationship between the ratio of $\left(f_{\mathrm{cu}}-f_{c 0}\right) / f_{c 0}$ and $\lambda_{f}$ and $v_{N}$ is shown in Figure 10, where $f_{\mathrm{cu}}$ and $f_{c 0}$ are the cube compressive strength of SFNS-CRC and CRC and $\lambda_{f}$ is the characteristic coefficient of steel fibers. Although the experimental data look like dispersed, the ratio of $\left(f_{\mathrm{cu}}-f_{c 0}\right) / f_{c 0}$ has an increasing tendency with the increasing $\lambda_{f}$ and $v_{N}$, respectively. Through the regression of test data mentioned above, an empirical formula of $f_{\mathrm{cu}}$ is put forward as follows:

$$
f_{\mathrm{cu}}=f_{0}\left(1+0.22 \lambda_{f}-0.12 \lambda_{f}^{2}\right)\left(1+0.11 v_{N}\right) .
$$

The comparison of $f_{\mathrm{cu}}$ calculated by equation (2) with the test results is shown in Figure 11. It can be seen that the calculation results are in good agreement with the test data. In this paper, the obtained data were corresponding to 0.42 water/cement ratio. For the purpose of extending the applicability of equations, the data of specimens with different water/cement ratios were collected from the different experiments finished by other researches to be employed for establishing the equations. They confirmed that the calculated value matches the experimental values well, which indicates equation (2) can be used to calculate $f_{\mathrm{cu}}$ of SFNSCRC when $f_{\mathrm{cu}}$ is below $60 \mathrm{MPa}$.

It can be seen from the test results in Figure 5(a) that the ratio of the compressive strength of the prism to that of the 


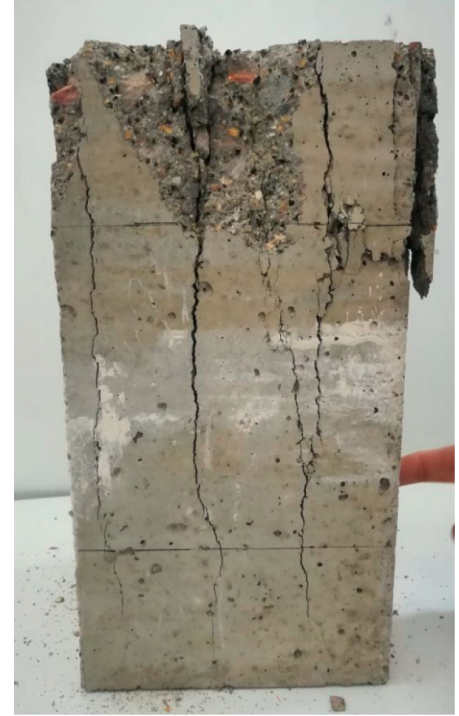

(a)

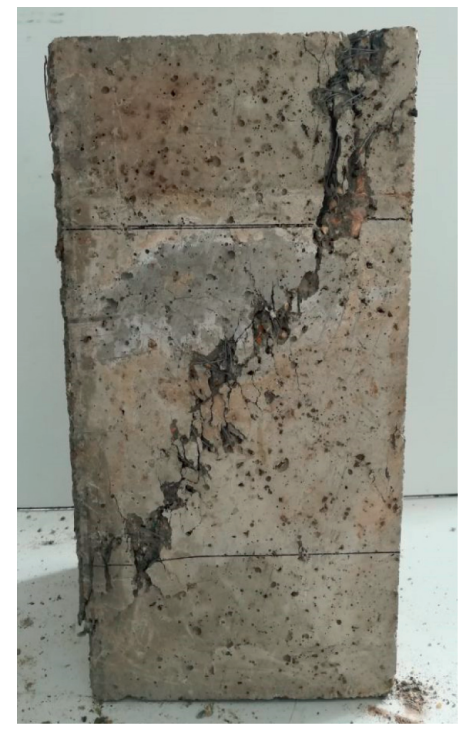

(d)

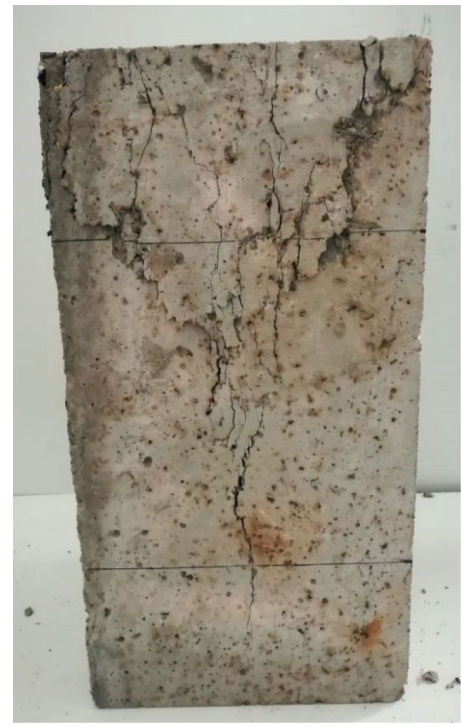

(b)

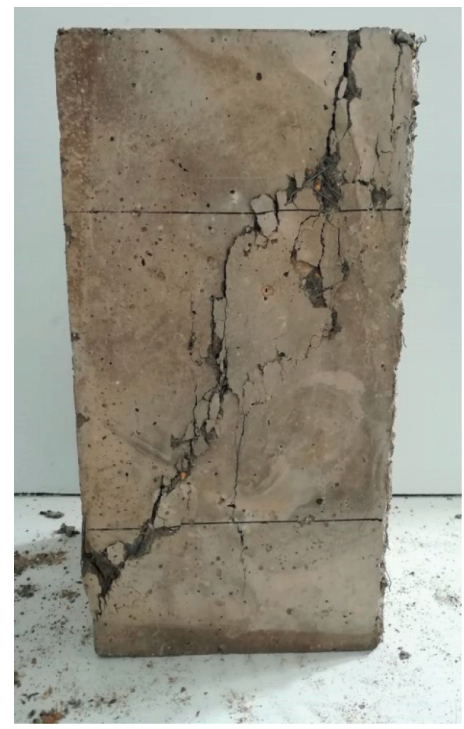

(e)

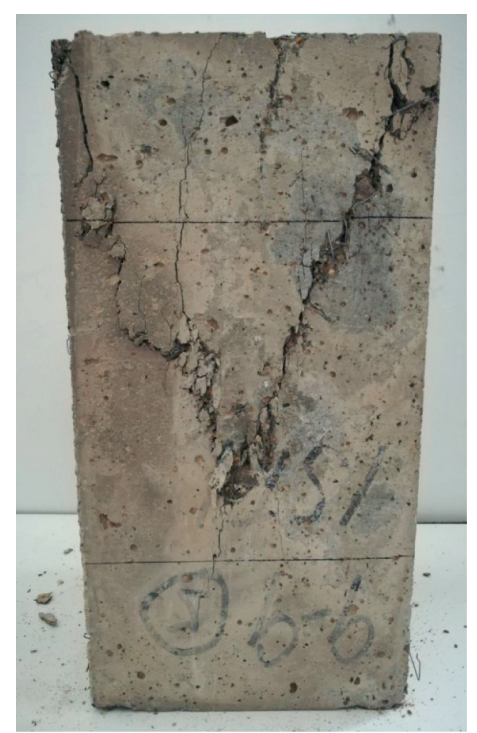

(c)

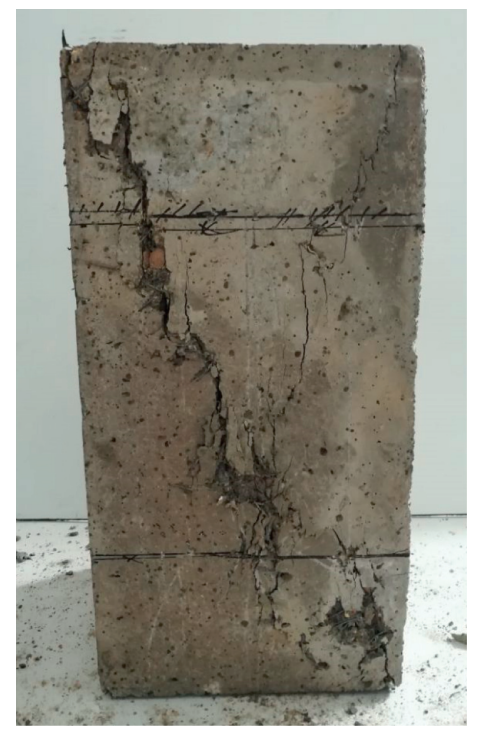

(f)

Figure 9: Failure modes of specimens. (a) CR5SF0. (b) CR5SF0.5. (c) CR5SF1.0. (d) CR5SF1.5. (e) CR5SF1NS1. (f) CR5SF1NS2.

cube for SFNS-CRC is the same as that for CRC, and there is a consistency between the compressive strength of the cube and the prism for SFNS-CRC and CRC. Therefore, the prism compressive strength of SFNS-CRC can be calculated in the same model as that for cube compressive strength of SFNS$\mathrm{CRC}$ as follows:

$$
f_{c}=f_{0}\left(1+0.22 \lambda_{f}-0.12 \lambda_{f}^{2}\right)\left(1+0.11 v_{N}\right),
$$

where $f_{\mathrm{c}}$ and $f_{0}$ are the prism compressive strength of SFNS-CRC and CRC, respectively.

4.2. Modulus of Elasticity. Modulus of elasticity is usually used in structure design. Many relationships between $f_{\mathrm{cu}}$ and $E_{c}$ have been set up in many studies. For example, the elastic modulus for normal concrete can be calculated as follows according to the Chinese standard "GB/T50081-2010" [49]:

$$
E_{\mathrm{c}}=\frac{10^{5}}{2.2+\left(34.7 / f_{\mathrm{cu}}\right)} \text {. }
$$

Zheng et al. [40] put forward a relationship between modulus of elasticity and compressive strength for rubberized concrete based on the ACI equation:

$$
E_{c}=4213.667 \sqrt{1.25 f_{\mathrm{cu}}} \text {. }
$$

Using the available data from the tests as well as those available from the database, Bompa et al. [50] suggested a prediction of $E_{c}$ for rubberized concrete by using the compressive strength: 


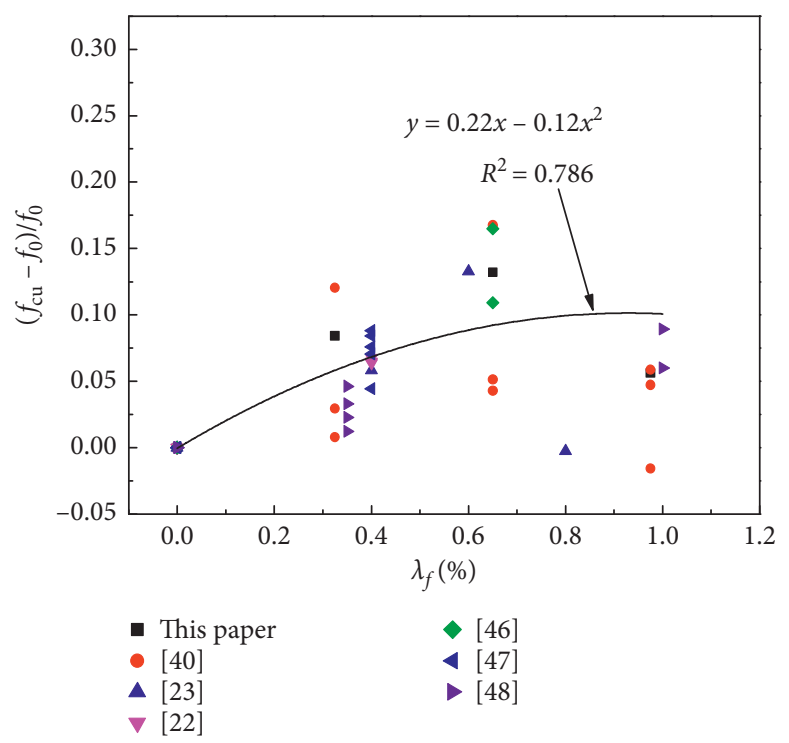

(a)

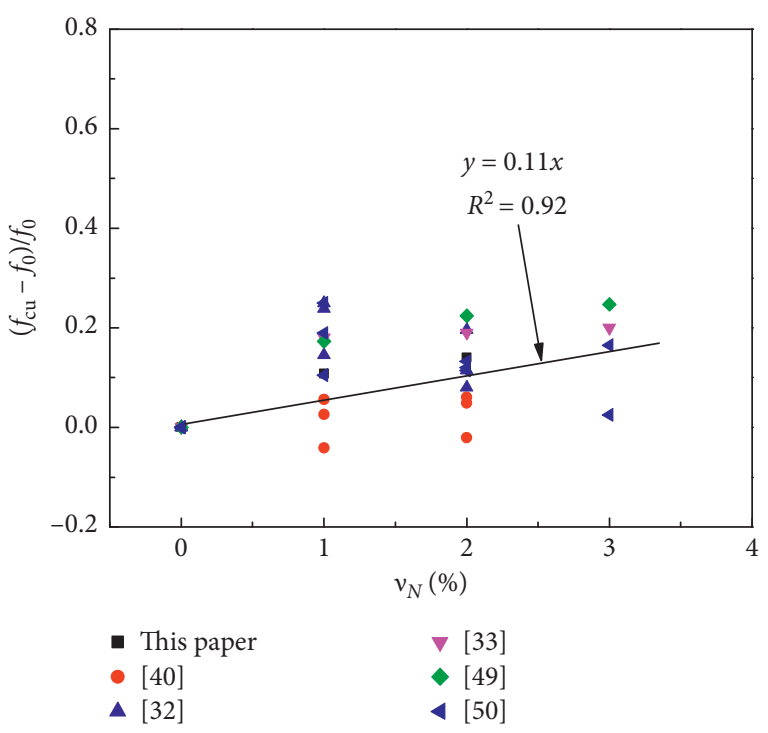

(b)

Figure 10: Relationship of $f_{\mathrm{cu}}$ with (a) $\lambda_{f}$ and (b) $v_{N}$.

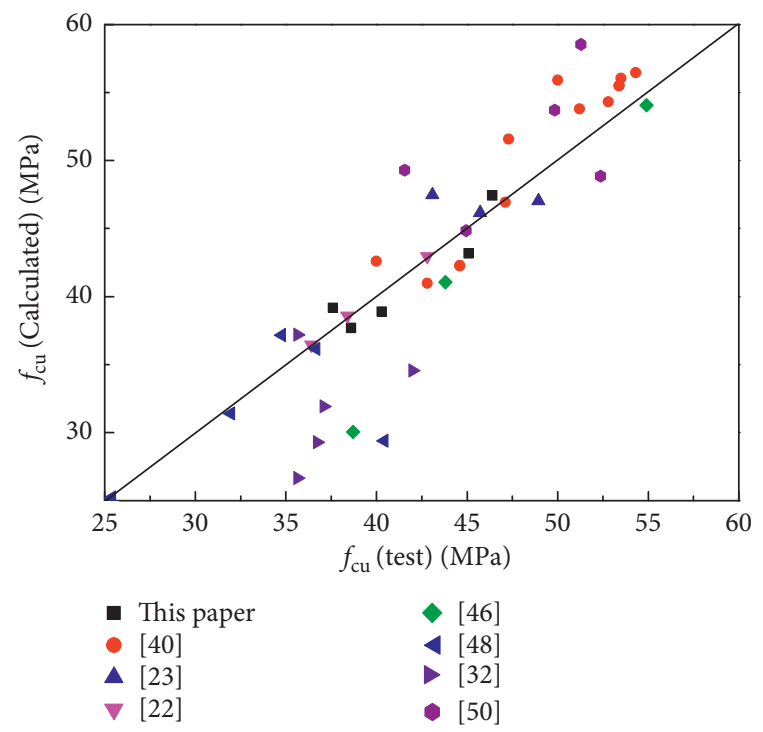

Figure 11: Comparison of $f_{\mathrm{cu}}$ between test and calculated data.

$$
E_{c}=12\left(\frac{0.8 \times f_{\mathrm{cu}}}{10}\right)^{2 / 3} \times 10^{3} .
$$

Based on the regression of the experimental data from this paper and previous studies [22,23,32,45,47], a formula of $E_{c}$ for SFNS-CRC is proposed as follows:

$$
E_{c}=\frac{10^{5}}{1.5+\left(90.5 / f_{\mathrm{cu}}\right)} \text {. }
$$

The comparison of calculated results by equations (5)-(7) with test results between $f_{\mathrm{cu}}$ and $E_{c}$ is drawn in Figure 12. It can be seen from the figure that equations (5)-(7) are in line with the test results well, which can be used to calculate the elastic modulus for SFNS-CRC by $f_{\mathrm{cu}}$.

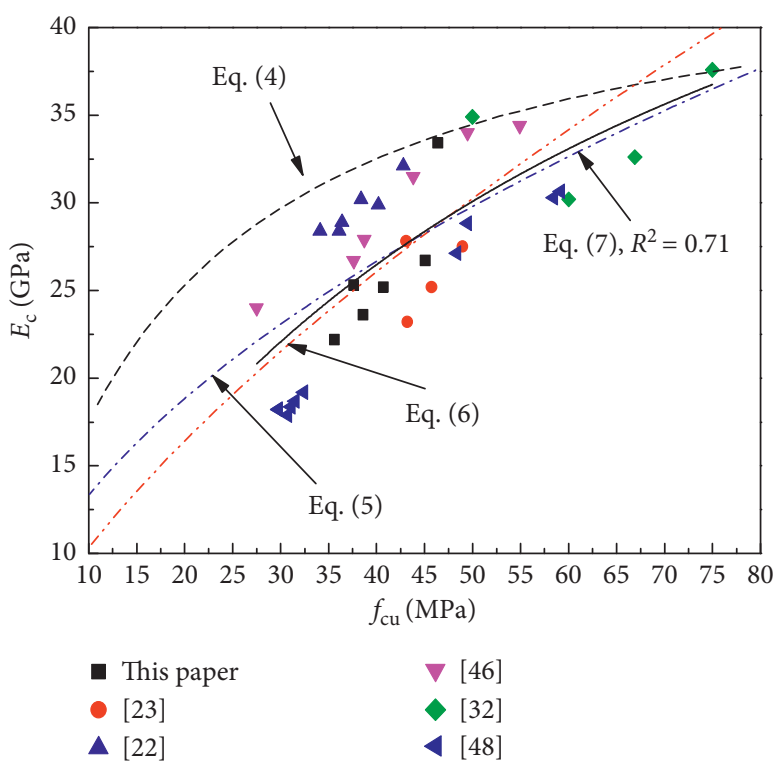

Figure 12: Relationship between $E_{c}$ and $f_{\mathrm{cu}}$.

It needs to be underlined that equation (7) is suitable for predicting $E_{c}$ of SFNS-CRC when $f_{\mathrm{cu}}$ is less than $60 \mathrm{MPa}$.

4.3. Peak Strain. It is observed from Table 2 that the peak strain $\varepsilon_{c}$ has the relationship with steel fiber volume contents $v_{f}$ and nanosilica replacement ratios $v_{N}$. Through the regression of test results from this paper, an empirical formula of $\varepsilon_{c}$ is put forward as follows:

$$
\varepsilon_{c}=\varepsilon_{0}\left(1+0.55 \lambda_{f}\right)\left(1+0.23 v_{N}\right),
$$

where $\varepsilon_{c}$ and $\varepsilon_{0}$ are the peak strain of SFNS-CRC and CRC, respectively. Generally, $\varepsilon_{0}$ increases with the increase of $f_{c}$. 


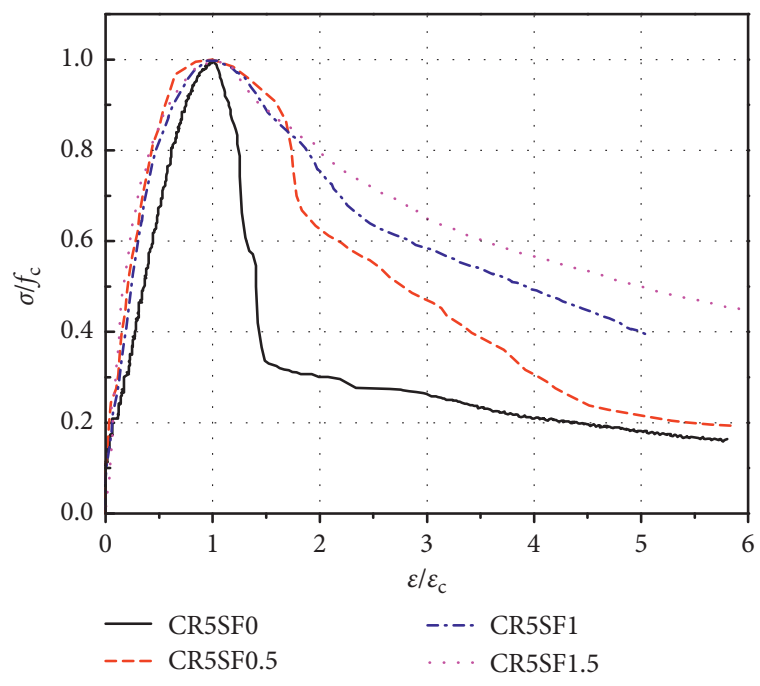

(a)

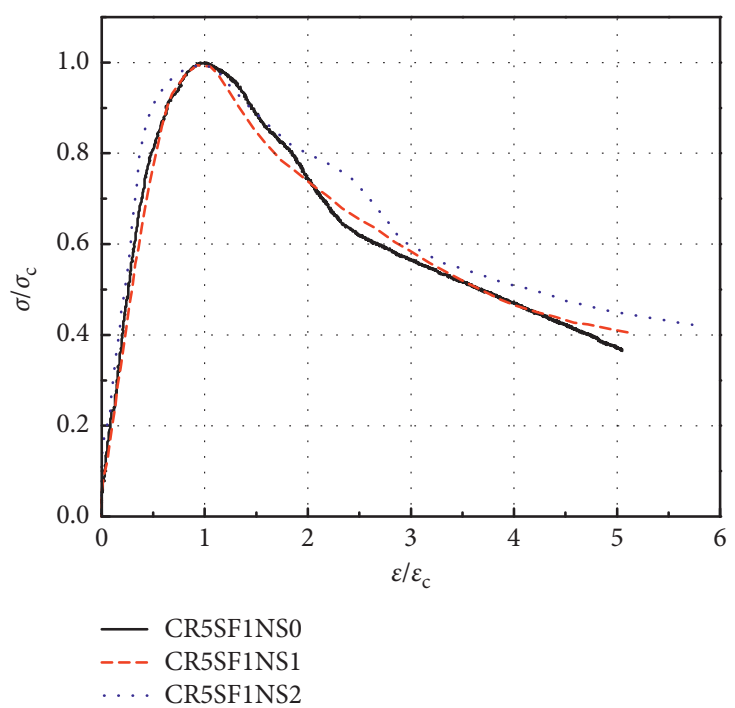

(b)

FIGURE 13: Normalized stress-strain curves of SFNS-CRC with different (a) $v_{f}$ and (b) $v_{N}$.

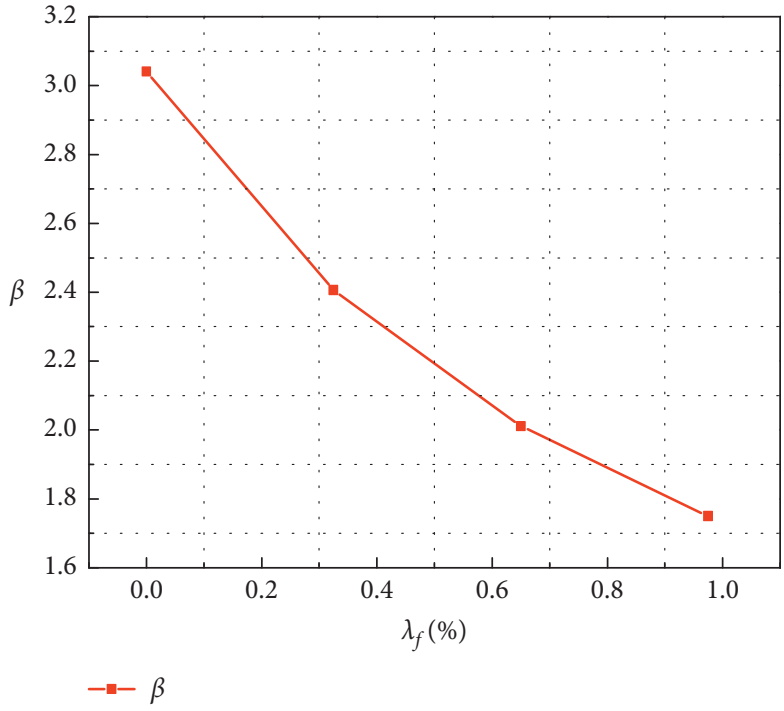

(a)

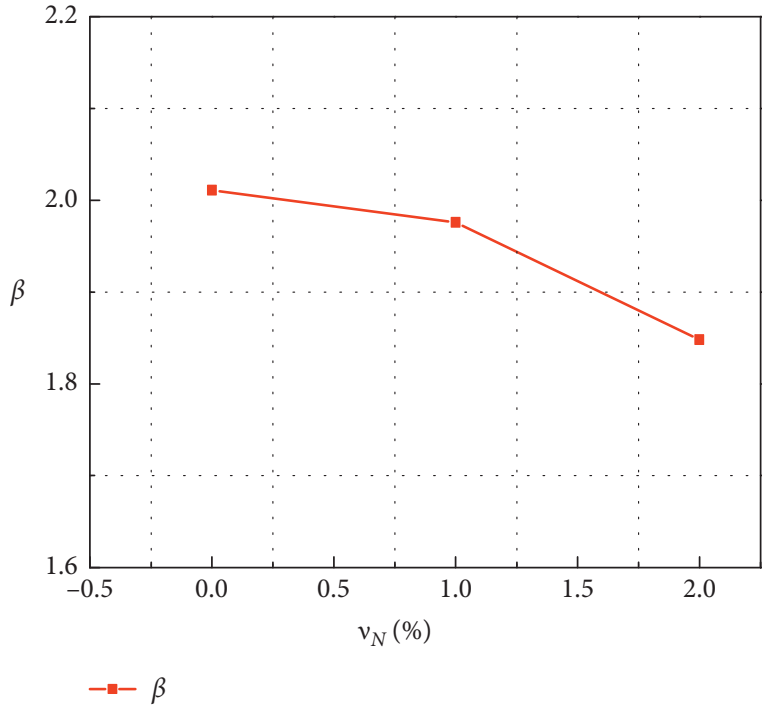

(b)

Figure 14: Relationship of $\beta$ with (a) $\lambda_{f}$ and (b) $\nu_{N}$.

An empirical formula developed by Li et al. [51] for predicting the peak strain for CRC is used in this paper as follows:

$$
\varepsilon_{0}=\left(1065.91+117.955 \sqrt{f_{\mathrm{c}}}\right) \times 10^{-6},
$$

where $f_{\mathrm{c}}$ is the prism compressive strength of CRC.

4.4. Stress-Strain Curve. The recorded load-deformation curves are transformed into the dimensionless form to analyze the characteristics of stress-strain curves, as shown in Figure 13. There are various equations to predict the stress- strain curve of concrete [52-59], in which the model proposed by Ezeldin and Balagaru [57] is brief and easy to use, that is,

$$
y=\frac{\beta x}{\beta-1+x^{\beta}},
$$

where $y=\sigma / f_{c}$, in which $\sigma$ is the stress under uniaxial compression and $f_{c}$ is the peak stress of SFNS-CRC under uniaxial compression; $x=\varepsilon / \varepsilon_{c}$, in which $\varepsilon$ is the strain under uniaxial compression and $\varepsilon_{c}$ is the peak strain of SFNS-CRC under uniaxial compression; and $\beta$ is the material parameter that depends on the shape of the stress-strain diagram.

According to the characteristics of the stress-strain 


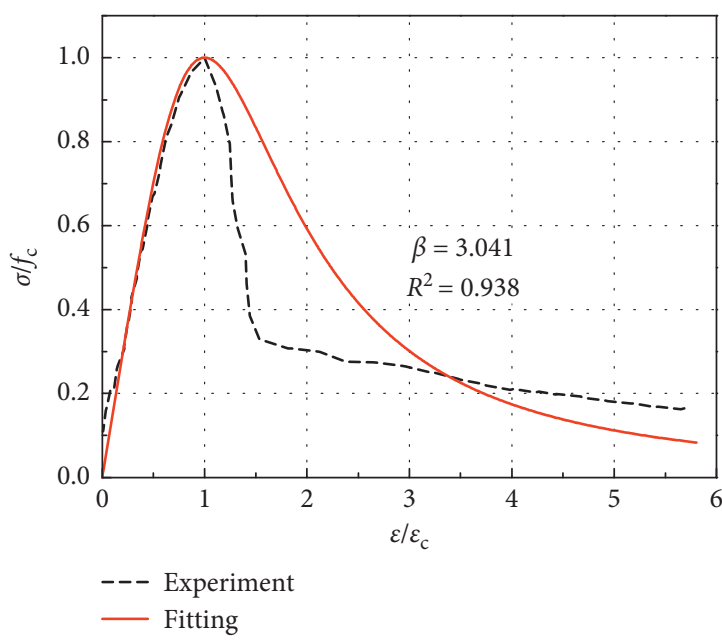

(a)

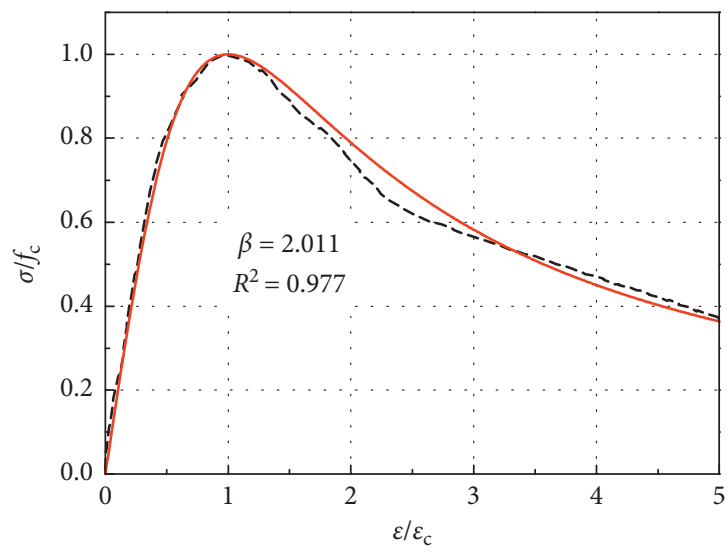

--- Experiment

- Fitting

(c)

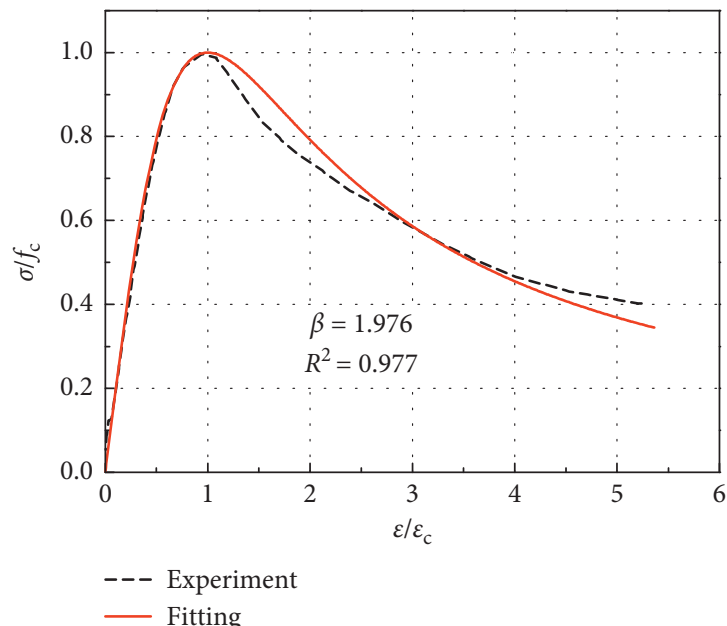

(e)

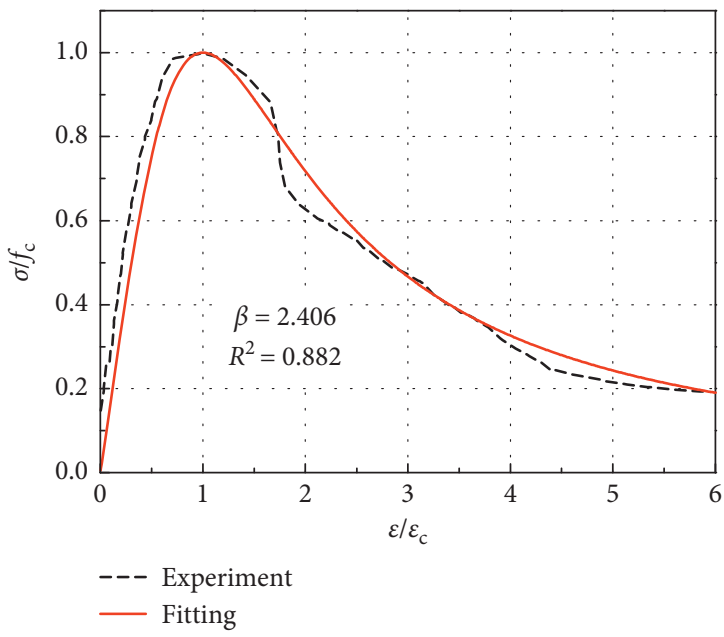

(b)

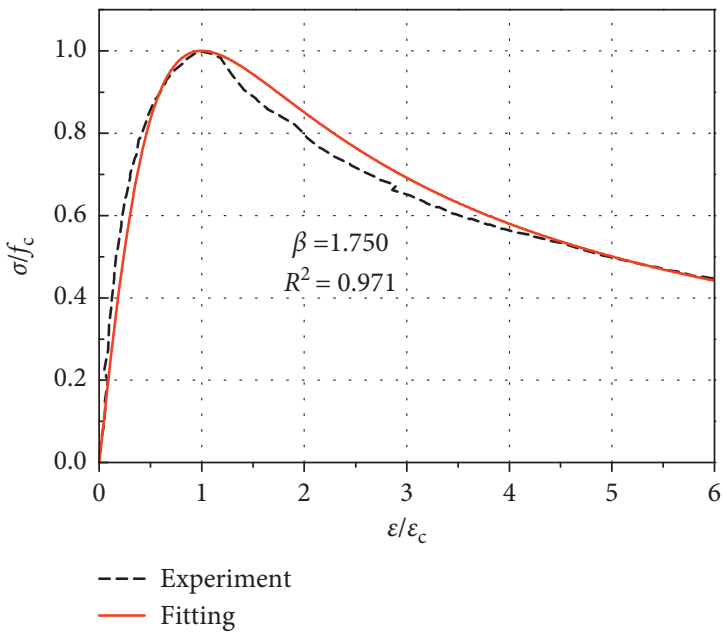

(d)

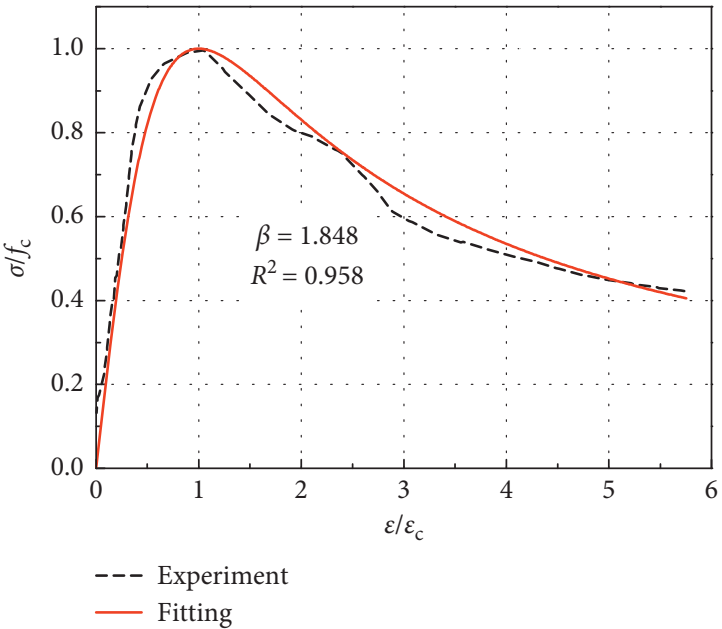

(f)

Figure 15: Comparison of the fitting curve and experiment curve. (a) CR5SF0. (b) CR5SF0.5. (c) CR5SF1.0. (d) CR5SF1.5. (e) CR5SF1NS1. (f) CR5SF1NS2.

curve, the following geometric boundary conditions are determined: $\quad \varepsilon=0, \quad \sigma=0 ; \quad \varepsilon=0, \quad \mathrm{~d} \sigma / \mathrm{d} \varepsilon=0 ; \quad \varepsilon=\varepsilon_{\mathrm{p}}$, $\mathrm{d} \sigma / \mathrm{d} \varepsilon=E_{c}$; and $\sigma=\sigma_{p}, \mathrm{~d} \sigma / \mathrm{d} \varepsilon=0$. Through satisfying the geometric boundary conditions mentioned above, the parameter $\beta$ of stress-strain curves can be calculated as follows: 


$$
\beta=\frac{1}{1-\left(f_{c} / \varepsilon_{c} E_{c}\right)} .
$$

The values of $\beta$ can be determined by values of $f_{c}, \varepsilon_{c}$, and $E_{c}$ from the measured stress-strain curves of SFNS-CRC or calculated by the equations of $f_{c}, \varepsilon_{c}$, and $E_{c}$ established previously in this paper, as illustrated in Figure 14. It can be seen that $\beta$ decreases with the increase of steel fiber volume contents and slightly decreases with the increase of the nanosilica content. The descending part of the stress-strain curve is affected by the $\beta$ value. As the value of $\beta$ decreases, the area under the stress-strain curve increases, which means the curve becomes flatter. It indicates $\beta$ can reflect the influence of $\lambda_{f}$ and $v_{N}$ on the strength and toughness of SFNSCRC. Through regression analysis, the equation of $\beta$ can be set up as follows by using $\lambda_{f}$ and $v_{N}$ as variables:

$$
\beta=2.94-1.34 \lambda_{f}-0.12 v_{N} k, \quad R^{2}=0.95 .
$$

The stress-strain curve can be predicted by using equations (3), (10), and (12). The comparison of fitted curves with experimental curves is shown in Figure 15. It can be observed that the calculated results by equation (10) fit well with the experimental results and the fitting coefficients are more than 0.9 except for that of CR5SF0.5.

\section{Conclusions}

The mechanical characteristics of CRC with different nanosilica replacement ratios and steel fiber volume contents have been experimentally studied through the uniaxial compressive tests on prism specimens. Based on the extensive test data and analysis, the following conclusions can be drawn:

(1) For the SFNS-CRC specimens with the different steel fiber and nanosilica contents, the ascending shapes of load-deformation curves are similar, while there is a difference in the descending part of the curves. With the addition of steel fibers, the SFNS-CRC specimens exhibit more ductile failure and maintain their integrity during testing. With the addition of nanosilica, the surface cracks of SFNS-CRC specimens become fine and dense.

(2) Both steel fibers and nanosilica have the better reinforcing effects on the compressive characteristics of CRC. The toughness index and energy dissipation capacity of SFNS-CRC in compression increase with the increasing steel fiber and nanosilica contents, respectively. The critical compressive strain of SFNSCRC significantly increases with the combined effect of steel fibers and nanosilica.

(3) By considering the effects of the characteristic parameter of steel fiber and nanosilica contents upon the compressive characteristics of CRC, the equations for compressive strength, modulus of elasticity, and critical compressive strain of SFNS-CRC were proposed by regression of experimental data, respectively. Then, a simple predicted model of the stress-strain curve for SFNS-CRC was proposed, which only contains one parameter $(\beta)$ and is easy to be used.

\section{Data Availability}

The data used to support the findings of this study are available from the corresponding author upon request.

\section{Conflicts of Interest}

The authors declare that they have no conflicts of interest.

\section{Acknowledgments}

The authors would like to thank the financial support of the National Natural Science Foundation of China (nos. U1704254 and 51808508) and the Key Scientific Research Projects of Henan Province (18A560022).

\section{References}

[1] F. Demir, B. Yesilata, P. Turgut, H. Bulut, and Y. Isiker, "Investigation of the effects of $\mathrm{pH}$, aging and scrap tire content on the dissolution behaviors of new scrap tire-concrete mixture structures," Journal of Cleaner Production, vol. 93, pp. 38-46, 2015.

[2] F. Pacheco-Torgal, Y. Ding, and S. Jalali, "Properties and durability of concrete containing polymeric wastes (tire rubber and polyethylene terephthalate bottles): an overview," Construction and Building Materials, vol. 30, pp. 488-494, 2012.

[3] M. Bravo and J. de Brito, "Concrete made with used tyre aggregate: durability-related performance," Journal of Cleaner Production, vol. 25, no. 2, pp. 42-50, 2012.

[4] B. S. Thomas, R. C. Gupta, and V. J. Panicker, "Recycling of waste tire rubber as aggregate in concrete: durability-related performance," Journal of Cleaner Production, vol. 112, pp. 504-513, 2016.

[5] Q. Han, Y. Wang, J. Xu, and Y. Xing, "Static behavior of stud shear connectors in elastic concrete-steel composite beams," Journal of Constructional Steel Research, vol. 113, pp. 115-126, 2015.

[6] A. Richardson, K. Coventry, V. Edmondson, and E. Dias, "Crumb rubber used in concrete to provide freeze-thaw protection (optimal particle size)," Journal of Cleaner Production, vol. 112, pp. 599-606, 2016.

[7] S. F. Wong and S. K. Ting, "Use of recycled rubber tires in normal and high-strength concretes," ACI Materials Journal, vol. 106, no. 4, pp. 325-332, 2009.

[8] O. A. Abaza and S. M. Shtayeh, "Crumbed rubber for nonstructural Portland cement concrete applications," Dirasat, vol. 37, no. 2, 2010.

[9] N. N. Eldin and A. B. Senouci, "Use of scrap tires in road construction," Journal of Construction Engineering and Management, vol. 118, no. 3, pp. 561-576, 1992.

[10] A. R. Pasandín and I. Pérez, "Fatigue performance of bituminous mixtures made with recycled concrete aggregates and waste tire rubber," Construction and Building Materials, vol. 157, pp. P26-P33, 2017.

[11] M. Alaa and A. Rashad, "Comprehensive overview about recycling rubber as fine aggregate replacement in traditional cementitious materials," International Journal of Sustainable Built Environment, vol. 5, no. 1, pp. 46-82, 2016. 
[12] L. Li, S. H. Ruan, and L. Zeng, "Mechanical properties and constitutive equations of concrete containing a low volume of tire rubber particles," Construction and Building Materials, vol. 70, pp. P291-P308, 2014.

[13] R. D. Neves and J. C. O. Fernandes De Almeida, "Compressive behaviour of steel fibre reinforced concrete," Structural Concrete, vol. 6, no. 1, pp. 1-8, 2005.

[14] R. S. Olivito and F. A. Zuccarello, "An experimental study on the tensile strength of steel fiber reinforced concrete," Composites Part B: Engineering, vol. 41, no. 3, pp. 246-255, 2010.

[15] X. Yi and X. Fan, "Flexural-tensile properties of layered steel fiber reinforced concrete," Jouranal of Wuhan University of Technology Materials Science Edition, vol. 24, no. 5, pp. 846-848, 2009.

[16] M. C. Nataraja, N. Dhang, and A. P. Gupta, "Stress-strain curves for steel-fiber reinforced concrete under Compression," Cement and Concrete Composites, vol. 21, no. 5-6, pp. 383-390, 1999.

[17] M. K. Ismail, A. A. A. Hassan, and A. A. Hussein, "Structural behaviour of reinforced concrete beams containing crumb rubber and steel fibres," Magazine of Concrete Research, vol. 69 , no. 18 , pp. 939-953, 2017.

[18] O. A. Abaza and Z. S. Hussein, "Flexural behavior of steel fiber-reinforced rubberized concrete," Journal of Materials in Civil Engineering, vol. 28, no. 1, 2016.

[19] N. Ganesan, J. Bharati Raj, and A. P. Shashikala, "Flexural fatigue behavior of self compacting rubberized concrete," Construction and Building Materials, vol. 44, pp. 7-14, 2013.

[20] A. Turatsinze, J.-L. Granju, and S. Bonnet, "Positive synergy between steel-fibres and rubber aggregates: effect on the resistance of cement-based mortars to shrinkage cracking," Cement and Concrete Research, vol. 36, no. 9, pp. 1692-1697, 2006.

[21] Y. Li and Y. Li, "Experimental study on performance of rubber particle and steel fiber composite toughening concrete," Construction and Building Materials, vol. 146, pp. 267-275, 2017.

[22] T. N. Ahmed, B. Bakar, and M. Hazizan, "Experimental investigation on compression toughness of rubberized steel fiber concrete," Construction and Building Materials, vol. 115, pp. 163-170, 2016.

[23] C. Fu, H. Ye, K. Wang, K. Zhu, and C. He, "Evolution of mechanical properties of steel fiber-reinforced rubberized concrete (FR-RC)," Composites Part B: Engineering, vol. 160, pp. 158-166, 2019.

[24] K. P. Chong and E. J. Garboczi, "Smart and designer structural material systems," Progress in Structural Engineering and Materials, vol. 4, no. 4, pp. 417-430, 2002.

[25] B.-W. Jo, C.-H. Kim, G.-H. Tae, and J.-B. Park, "Characteristics of cement mortar with nano- $\mathrm{SiO}_{2}$ particles," Construction and Building Materials, vol. 21, no. 6, pp. 1351-1355, 2007.

[26] J. J. Gaitero, I. Campillo, and A. Guerrero, "Reduction of the calcium leaching rate of cement paste by addition of silica nanoparticles," Cement and Concrete Research, vol. 38, no. 89, pp. 1112-1118, 2008.

[27] H. M. Jennings, J. W. Bullard, J. J. Thomas, J. E. Andrade, J. J. Chen, and G. W. Scherer, "Characterization and modeling of pores and surfaces in cement paste," Journal of Advanced Concrete Technology, vol. 6, no. 1, pp. 5-29, 2008.

[28] S. Uthaman, V. Vishwakarma, R. P. George et al., "Enhancement of strength and durability of fly ash concrete in seawater environments: synergistic effect of nanoparticles,"
Construction and Building Materials, vol. 187, pp. 448-459, 2018.

[29] B. B. Mukharjee and S. V. Barai, "Influence of incorporation of nano-silica and recycled aggregates on compressive strength and microstructure of concrete," Construction and Building Materials, vol. 71, pp. 570-578, 2014.

[30] M. Amin and K. Abu El-hassan, "Effect of using different types of nano materials on mechanical properties of high strength concrete," Construction and Building Materials, vol. 80, pp. 116-124, 2015.

[31] A. Nazari and S. Riahi, "Retracted: abrasion resistance of concrete containing $\mathrm{SiO}_{2}$ and $\mathrm{Al}_{2} \mathrm{O}_{3}$ nanoparticles in different curing media," Energy and Buildings, vol. 43, no. 10, pp. 2939-2946, 2011.

[32] B. S. Mohammed and M. Adamu, "Mechanical performance of roller compacted concrete pavement containing crumb rubber and nano silica," Construction and Building Materials, vol. 159, pp. 234-251, 2018.

[33] B. S. Mohammed, A. B. Awang, S. S. Wong, and C. P. Nhavene, "Properties of nano silica modified rubbercrete," Journal of Cleaner Production, vol. 119, pp. 66-75, 2016.

[34] GB 8076-2008, “Concrete admixtures," China National Standards, China, 2008, in Chinese.

[35] GB 175-2007, "Common portland cement," China National Standards, China, 2007, in Chinese.

[36] GBT 14684-2011, "Sand for construction," China National Standards, China, 2011, in Chinese.

[37] China Architecture \& Building Press, Standard for Test Method of Mechanical Properties on Ordinary Concrete: GB/ T50081, China Architecture \& Building Press, Beijing, China, 2002.

[38] CESC, Standard Test Methods for Fiber Reinforced Concrete: CECS 13: 2009, China Planning Press, Beijing, China, 2010.

[39] C. S. Whitney, "Discussion on V.P Jensen's paper," ACI Journal Proceedings, vol. 39, no. 3, 1943.

[40] L. Zheng, X. S. Huo, and Y. Yuan, "Strength, modulus of elasticity, and brittleness index of rubberized concrete," Journal of Materials in Civil Engineering, vol. 20, no. 11, pp. 692-699, 2008.

[41] S. Shah and B. V. Rangan, "Fiber reinforced concrete properties," Journal of The American Concrete Institute, vol. 68, no. 2, pp. 126-135, 1997.

[42] N. Balaguru and S. P. Shah, Fiber Reinforced Cement Composites, pp. 179-214, McGraw-Hill Education, New York, NY, USA, 1992.

[43] Y. Wang, J. Chen, D. Gao, and E. Huang, "Mechanical properties of steel fibers and nanosilica modified crumb rubber concrete," Advances In Civil Engineering, vol. 2018, Article ID 6715813, 10 pages, 2018.

[44] K. Marar, Ö. Eren, and T. Çelik, "Relationship between impact energy and compression toughness energy of high-strength fiber-reinforced concrete," Materials Letters, vol. 47, no. 4-5, pp. 297-304, 2001.

[45] J. C. Carroll and N. Helminger, "Fresh and hardened properties of fiber-reinforced rubber concrete," Journal of Materials in Civil Engineering, vol. 28, no. 7, 2016.

[46] T. N. Ahmed, B. H. Abu Bakar, H. M. Akil, and A. H. Alani, "Fracture characteristics of plain and steel fiber reinforced rubberized concrete," Construction and Building Materials, vol. 152, pp. 414-442, 2017.

[47] M. K. Ismail and A. A. A. Hassan, "Shear behaviour of largescale rubberized concrete beams reinforced with steel fibres," Construction and Building Materials, vol. 140, pp. 43-57, 2017. 
[48] B. S. Mohammed and M. Adamu, "Non-destructive evaluation of nano silica-modified roller-compacted rubbercrete using combined sonreb and response surface methodology," Road Materials and Pavement Design, vol. 20, no. 4, pp. 815-835, 2019.

[49] GB 50010-2010, Code for Design of Concrete Structures, China National Standards, China, 2010, in Chinese.

[50] D. V. Bompa, A. Y. Elghazouli, B. Xu, P. J. Stafford, and A. M. Ruiz-Teran, "Experimental assessment and constitutive modelling of rubberised concrete materials," Construction and Building Materials, vol. 137, pp. 246-260, 2017.

[51] D. Li, Y. Zhuge, R. Gravina, and J. E. Mills, "Compressive stress strain behavior of crumb rubber concrete (CRC) and application in reinforced CRC slab," Construction and Building Materials, vol. 166, pp. 745-759, 2018.

[52] L. S. M. Hsu and C. T. T. Hsu, "Stress-strain behavior of steel fiber high-strength concrete under compression," $A C I$ Structural Journal, vol. 91, no. 4, pp. 448-457, 1994.

[53] D. Gao, L. Zhang, and M. Nokken, "Compressive behavior of steel fiber reinforced recycled coarse aggregate concrete designed with equivalent cubic compressive strength," Construction and Building Materials, vol. 141, pp. 235-244, 2017.

[54] S. Luo, S. Ye, J. Xiao, J. Zheng, and Y. Zhu, "Carbonated recycled coarse aggregate and uniaxial compressive stressstrain relation of recycled aggregate concrete," Construction and Building Materials, vol. 188, pp. 956-965, 2018.

[55] M. A. Mansur, M. S. Chin, and T. H. Wee, "Stress-strain relationship of high-strength fiber concrete in compression," Journal of Materials in Civil Engineering, vol. 11, no. 1, pp. 21-29, 1999.

[56] J. Zhou, J. Pan, and C. K. Y. Leung, "Mechanical behavior of fiber-reinforced engineered cementitious composites in uniaxial compression," Journal of Materials in Civil Engineering, vol. 27, no. 1, Article ID 04014111, 2014.

[57] S. Ezeldin and N. Balaguru, "Normal and high-strength fiberreinforced concrete under compression," Journal of Materials in Civil Engineering, vol. 4, no. 4, pp. 415-429, 1992.

[58] Z. Guo, Test and Constitution Relationship of Strength and Deformation of Concrete Experimental Foundation and Constitutive Relations, Tsinghua University Press, Beijing, China, 1997.

[59] B. S. Thomas and R. Chandra Gupta, "Properties of high strength concrete containing scrap tire rubber," Journal of Cleaner Production, vol. 113, pp. 86-92, 2016. 